\title{
ROTational AThErectomy in acute coronary syndrome: early and midterm outcomes from a multicentre registry
}

Iannaccone, Mario ; Piazza, Fabio ; Boccuzzi, Giacomo G ; D'Ascenzo, Fabrizio ; Latib, Azeem ; Pennacchi, Mauro ; Rossi, Marco Luciano ; Ugo, Fabrizio ; Meliga, Emanuele ; Kawamoto, Hiroyoshi ; Moretti, Claudio ; Ielasi, Alfonso ; Garbo, Roberto ; Frangieh, Antonio H ; Hildick-Smith, David ; Templin, Christian ; Colombo, Antonio ; Sardella, Gennaro

DOI: https://doi.org/10.4244/EIJ-D-15-00485

Posted at the Zurich Open Repository and Archive, University of Zurich ZORA URL: https://doi.org/10.5167/uzh-134610

Journal Article

Published Version

Originally published at:

Iannaccone, Mario; Piazza, Fabio; Boccuzzi, Giacomo G; D’Ascenzo, Fabrizio; Latib, Azeem; Pennacchi, Mauro; Rossi, Marco Luciano; Ugo, Fabrizio; Meliga, Emanuele; Kawamoto, Hiroyoshi; Moretti, Claudio; Ielasi, Alfonso; Garbo, Roberto; Frangieh, Antonio H; Hildick-Smith, David; Templin, Christian; Colombo, Antonio; Sardella, Gennaro (2016). ROTational AThErectomy in acute coronary syndrome: early and midterm outcomes from a multicentre registry. EuroIntervention, 12(12):1457-1464.

DOI: https://doi.org/10.4244/EIJ-D-15-00485 


\section{When you're sure, you can reassure}

\section{Eurolntervention}

Official Journal of EuroPCR and the European Associatio of Percutaneous Cardiovascular Interventions (EAPC)

\section{ROTational AThErectomy in acute coronary syndrome: early and midterm outcomes from a multicentre registry}

Published on 20 December 2016

Mario lannaccone ${ }^{1 *}$, MD; Fabio Piazza 2 , MD; Giacomo G. Boccuzzi², MD; Fabrizio D'Ascenzo ${ }^{1}$, MD; Azeem Latib ${ }^{3}$, MD; Mauro Pennacchi ${ }^{4}$, MD; Marco Luciano Rossi ${ }^{5}, \mathrm{MD}$; Fabrizio Ugo ${ }^{2}, \mathrm{MD}$; Emanuele Meliga ${ }^{6}, \mathrm{MD}$; Hiroyoshi Kawamoto ${ }^{7}, \mathrm{MD}$; Claudio Moretti ${ }^{1}, \mathrm{MD}$; Alfonso lelasi $^{8}, \mathrm{MD}$; Roberto Garbo ${ }^{2}, \mathrm{MD}$; Antonio H. Frangieh ${ }^{9}$, MD; David Hildick-Smith ${ }^{10}$, MD; Christian Templin ${ }^{9}$, MD Antonio Colombo ${ }^{3}, \mathrm{MD}$; Gennaro Sardella ${ }^{4}, \mathrm{MD}$

1. "Città della Scienza e della Salute", University of Turin, Turin, Italy; 2. Cardiology Department, Ospedale San Giovanni Bosco, Turin, Italy; 3. San Raffaele Scientific Institute, Milan, Italy and EMO-GVM Centro Cuore Columbus, Milan, Italy; 4. Department of Cardiovascular, Respiratory and Morphologic Sciences, Policlinico Umberto I, "Sapienza" University of Rome, Rome, Italy; 5. Division of Cardiology, Istituto Humanitas, Milan, Italy; 6. Interventional Cardiology Unit, A.O. Ordine Mauriziano Umberto I, Turin, Italy; 7. Interventional Cardiology Unit, New Tokyo Hospital, Chiba, Japan; 8. Department of Cardiology, Azienda Ospedaliera Bolognini Seriate, Bergamo, Italy; 9. Department of Cardiology, University Heart Center, University Hospital Zürich, Zürich, Switzerland; 10. Department of Cardiology, Sussex Cardiac Centre, Brighton, United Kingdom

Aims: The safety and efficacy of rotational atherectomy (RA) in patients presenting with non-ST-elevation myocardial infarction (NSTE-ACS) remain to be defined. The aim of our study was to assess the safety and efficacy of RA in NSTE-ACS patients with reference to both short- and long-term follow-up.

Methods and results: This was an observational retrospective registry which enrolled all consecutive patients undergoing RA, comparing patients with stable angina (SA) and NSTE-ACS. In addition, ACS patients were matched with those not undergoing RA. The primary endpoint was angiographic success. Procedural complications and in-hospital MACE were secondary endpoints along with MACE during follow-up. One thousand three hundred and eight patients were included: $37 \%$ (484) with an NSTE-ACS diagnosis and 63\% (824) in the SA group Angiographic success did not differ between the groups (98.8\% vs. $99.2 \%$, $\mathrm{p}=0.57$ ). By univariate analysis procedural complications were more frequent in the NSTE-ACS group $(11.3 \%$ vs. $8.0 \%, p=0.04)$. In-hospital MACE rates were comparable $(5.7 \%$ vs. $5.8 \%, p=0.93)$; by multivariate analysis NSTE-ACS patients showed a non-significant trend towards a higher risk of adverse events (HR 2.39, Cl: 0.96-5.96, $p=0.061)$. MACE after a median of 27.9 months was significantly higher in the NSTE-ACS group compared with the SA group (32.4\% vs. $24.2 \%$, log-rank $\mathrm{p}<0.001$ ), results confirmed by multivariate analysis. After propensity score matching, NSTE-ACS patients undergoing RA had similar outcomes to ACS patients who did not undergo RA ( $16 \%$ vs. $13 \%$, log-rank $p=0.14$ ).

Conclusions: Rotational atherectomy has similar safety and angiographic outcome in patients with NSTE-ACS or SA. The higher rate of adverse cardiac events at follow-up in NSTE-ACS patients undergoing RA is comparable with a matched population of NSTE-ACS patients not undergoing RA. 